\title{
APLIKASI MEDIA AUDIO VISUAL SEBAGAI UPAYA PENINGKATAN PENGETAHUAN REMAJA BANDARJO UNGARAN BARAT SEMARANG
}

\author{
Zumrotul Choiriyyah $^{1)}$, Abdul Wakhid ${ }^{2)}$ \\ 1. Universitas Ngudi Waluyo \\ 2. Universitas Ngudi Waluyo \\ E-mail: zumrotulnwu@gmail.com
}

\begin{abstract}
Abstrak
Penelitian ini dilatar belakangi oleh menurunnya minat remaja di Kelurahan Bandarjo Kecamatan Ungaran Barat akan adanya kegiatan Pusat Informasi dan Konseling Remaja (PIKR) yang setiap tahun semakin berkurang. Bahkan tiga bulan terakhir kegiatan tersebut sudah tidak berjalan lagi. Hasil wawancara terhadap kader kesehatan di kelurahan Bandarjo mengatakan bahwa kegiatan PIKR kelurahan Bandarjo belum aktif kembali karena kurangnya kesesuaian waktu pelaksanaan kegiatan tersebut dengan kesibukan remaja. Penelitian ini bertujuan untuk mengetahui gambaran pelaksanaan kegiatan PIKR di kelurahan Bandarjo Ungaran Barat Kabupaten Semarang. Jenis penelitian ini adalah deskriptif analitik. Penelitian ini bertujuan untuk mengetahui gambaran pelaksanaan kegiatan PIKR melalui penggunaan media audio visual dengan materi bahaya merokok dan video HIV/AIDS. Sampelnya adalah remaja yang berada di wilayah Kelurahan Bandarjo Ungaran Barat. Tehnik pengambilan sampel adalah total sampling. Analisis menggunakan analisis univariate dan bivariate. .Hasil penelitian menunjukkan gambaran pelaksanaan kegiatan PIKR melalui penggunaan media audio visual dengan materi bahaya merokok sejumlah kehadiran remaja adalah 14 remaja. Gambaran pelaksanaan kegiatan PIKR melalui penggunaan media audio visual dengan topik HIV/AIDS sejumlah 18 remaja. Ada perbedaan pengetahuan sebelum dan sesudah diberi video tentang HIV/AIDS dengan signifikansi 0,000 .
\end{abstract}

Kata kunci : Media audio visual, kunjungan,PIKR

\section{AUDIO VISUAL APLICATION AS IMPROVEMENT OF VISITED ADULT TO PIKR MOVEMENT IN BANDARJO UNGARAN BARAT SEMARANG}

\begin{abstract}
This study is based on the decreasing interest of adolescentsabout the activity of Youth Information and Counseling Center (PIKR) which decrease every year in Bandarjo Subdistrict, West Ungaran District. The results of interviews on health cares in Bandarjo said that the PIKR activities in Bandarjo have not been active yet because of the lack of matching of the activity time with the busyness of adolescent. This study aims to find out the description of the implementation of PIKR activities in Bandarjo, Ungaran, Semarang Regency. The type of this research is descriptive analytic. This study aims to find out the description of the implementation of PIKR activities through the use of audio visual media with material about the danger of smoking and video HIV / AIDS. Samples are teenagers residing in Bandarjo. The sampling technique is total sampling. Analysis using univariate and bivariate analysis. The results of this study show the description of the implementation of PIKR activities through the use of audio visual media with the dangers of smoking a number of adolescents present is 14 teenagers. Description of the implementation of PIKR activities through the use of audio visual media on HIV / AIDS topic of 18 adolescents. There is a difference of knowledge before and after being given a video about HIV / AIDS with a significance of 0.000 .
\end{abstract}

Keyword: Media, audio visual, Visite, PIKR 


\section{Pendahuluan}

Penelitian ini dilatar belakangi oleh menurunnya minat remaja di Kelurahan Bandarjo Kecamatan Ungaran Barat akan adanya kegiatan Pusat Informasi dan Konseling Remaja (PIKR) yang setiap tahun semakin berkurang. Bahkan tiga bulan terakhir kegiatan tersebut sudah tidak berjalan lagi. Hasil wawancara terhadap kader kesehatan di kelurahan Bandarjo mengatakan bahwa kegiatan PIKR kelurahan Bandarjo belum aktif kembali karena kurangnya kesesuaian waktu pelaksanaan kegiatan tersebut dengan kesibukan remaja. Selain mengikuti kegiatan PIKR tersebut mereka juga mempunyai kegiatan di sekolah, di kampus maupun di tempat kerja.

Di sisi lain hasil wawancara dengan remaja mengatakan bahwa selain kesibukan di kampus, mereka mengatakan bahwa kurangnya minat remaja dalam kegiatan tersebut dikarenakan belum merasa bahwa PIKR dapat memberikan wacana tambahan ilmu. Mereka dapat memperoleh informasi tentang kesehatan remaja dari internet dan pelajaran di kampus atau sekolah. Dengan kondisi tersebut peneliti mempunyai dugaan bahwa kurangnya minat remaja dalam kegiatan PIKR tersebut disebabkan oleh tidak sesuainya jadwal, kesibukan remaja di sekolah, kampus maupun tempat kerja. Selain itu kegiatan tersebut kurang menambah wawasan bagi remaja, dan terkesan kegiatan yang dilakukan secara statis. Oleh karena itu perlu adanya kegiatan PIKR yang lebih menarik, tidak hanya sekedar memberikan penyuluhan tentang kesehatan reproduksi, napza, seks bebas dan lainnya.

PIKR adalah kepanjangan dari Pusat Informasi dan Konsultasi Remaja. Sebenarnya PIKR ini bergerak berada di bawah naungan BKKBN. Aplikasi media audio visual adalah salah satu upaya untuk meningkatkan minat remaja dalam kegiatan tersebut. Kemajuan teknologi, dengan media audio visual yang menarik, remaja akan memusatkan perhatian pada materi yang tersaji, tidak hanya sekedar mendengarkan ceramah. Media audio visual ini diharapkan lebih interaktif dan memberikan efek yang baik bagi remaja. Diharapkan dengan media yang menarik merangsang minat remaja dalam kegiatan PIKR di kelurahan Bandarjo 


\section{Tinjauan Teoritis}

\section{Pengertian}

Pusat Informasi dan Konseling Kesehatan Reproduksi Remaja (PIK-KRR) oleh BKKBN dibagimenjadi dua yaitu: Pusat Informasi dan Konseling Remaja (PIK Remaja) dan Pusat Informasi danKonseling Mahasiswa (PIK Mahasiswa)

Pusat Informasi dan Konseling Remaja (PIK-Remaja) adalah suatu wadah kegiatan program PKBR yang dikelola dari, oleh dan untuk remaja guna memberikan pelayanan informasi dan konseling tentang Perencanaan Kehidupan Berkeluarga Bagi Remaja serta kegiatan-kegiatan penunjang lainnya. PIK Remaja adalah nama generik. Untuk menampung kebutuhan program PKBR dan menarik minat remaja datang ke PIK remaja, nama generik ini dapat dikembangkan dengan nama-nama yang sesuai dengan kebutuhan program dan selera remaja setempat.

\section{Tujuan PIKR}

Tujuan umum dari PIK Remaja adalah untuk memberikan informasi PKBR, Pendewasaan UsiaPerkawianan, Keterampilan Hidup (Life Skills), pelayanan konseling dan rujukan PKBR.Disamping itu, juga dikembangkan kegiatan-kegiatan lain yang khas dan sesuai minat dankebutuhan remaja untuk mencapai Tegar Remaja dalam rangka tegar Keluarga gunamewujudkan Keluarga Kecil Bahagia Sejahtera. Ruang lingkup PIK Remaja meliputi aspek-aspek kegiatan pemberian informasi KRR, Pendewasaan Usia Perkawinan, Keterampilan Hidup (Life Skills), pelayanan konseling, rujukan,pengembangan jaringan dan dukungan, serta kegiatan-kegiatan pendukung lainnya sesuaidengan ciri dan minat remaja. PIK Remaja tidak mengikuti tingkatan wilayah administrasi seperti tingkat desa, tingkat kecamatan, tingkat kabupaten/kota atau provinsi. Artinya PIK Remaja dapat melayani remaja lainnya yang berada di luar lokasi wilayah administrasinya. PIK Remaja dalam penyebutannyabisa dikaitkan dengan tempat dan institusi pembinanya seperti PIK Remaja Sekolah, PIKRemaja Masjid, PIK remaja Pesantren, dan lain-lain.Pengelola PIK Remaja adalah pemuda/remaja yang pnya komitmen dan mengelola langsungPIK Remaja serta telah mengikuti pelatihan dengan mempergunakan modul dan kurikulumstandard yang telah disusun oleh BKKBN atau yang sejenis. Pengelola PIK Remaja terdiri dariKetua, Bidang Administrasi, Bidang Program dan Kegiatan, Pendidik Sebaya, dan 
KonselorSebaya.Pembina PIK Remaja adalah seseorang yang mempunyai kepedulian yang tinggi terhadapmasalah-masalah remaja, memberikan dukungan dan aktif membina PIK Remaja, baik yangberasal dari Pemerintah, Lembaga Swadaya Masyarakat (LSM) atau organisasi. Materi dan Isi Pesan (assets) yang diberikan; 2) Ciri Kegiatan yang dilakukan; 3)Dukungan danJaringan (resources) yang dimiliki. Adapun ciri-ciri setiap tahapan sebagai berikut: Inggris, browsing internet, dan lain-lain.Masa remaja merupakan masa peralihan dari anakanakke masa dewasa. Kehidupan remajamerupakan kehidupan yang sangat menentukan bagi kehidupan masa depan mereka selanjutnya. Masa remaja seperti ini oleh Bank Dunia disebut sebagai masa transisi kehidupan remaja. Transisi kehidupan remaja oleh Bank Dunia dibagi menjadi 5 hal (Youth Five Life Transitions). Transisi kehidupan yang dimaksud menurut Progress Report World Bank adalah:

1. Melanjutkan sekolah (continue learning)

2. Mencari pekerjaan (start working)

3. Memulai kehidupan berkeluarga (form families)

4. Menjadi anggota masyarakat (exercise citizenship)

5. Mempraktekkan hidup sehat (practice healthy life).

Program PKBR (Penyiapan Kehidupan Berkeluarga Bagi Remaja) yang dilaksanakan berkaitandengan bidang kehidupan yang kelima dari transisi kehidupan remaja dimaksud, yaknimempraktekkan hidup secara sehat (practice healthy life). Empat bidang kehidupan lainnya yang akan dimasuki oleh remaja sangat ditentukan oleh berhasil tidaknya remaja mempraktekkankehidupan yang sehat. Dengan kata lain apabila remaja gagal berperilaku sehat, kemungkinan besar remaja yang bersangkutan akan gagal pada empat bidang kehidupan yang lain. Dari datadatayang berkaitan dengan gambaran perilaku sehat remaja, khususnya yang berhubungan dengan risiko TRIAD KRR (Seksualitas, NAPZA, HIV dan AIDS), tampaknya sebagian remaja Indonesia berperilaku tidak sehat.

\section{Metode Penelitian}

Tempat dan Waktu Penelitian dilaksanakan di Kelurahan Bandarjo Kecamatan Ungaran Barat Kabupaten Semarang. Sasaran adalah Remaja di wilayah Kelurahan Bandarjo Kecamatan Ungaran Barat Kabupaten Semarang. Studi ini menggunakan teknik studi 
descriptive analiticatas kunjungan remaja pada kegiatan PIKR di Kelurahan BandarjoUngaran Barat. Teknik pengambilan sampel dilakukan dengan metode total sampling yaitu pengambilan seluruh sampel dengan tetap memperhatikan kriteria yang telah ditetapkan. Jumlah peserta remaja adalah sekitar 20 orang. Teknik pengumpulan data dengan cara melakukan pertemuan di Kelurahan Bandarjo saat kegiatan PIKR berlangsung setiap minggu ke dua tiap bulannya. Analisis Data adalah analisis univariat dan bivariat.

Analisis univariate yaitu analisis yang mendeskripsikan distribusi frekuensi pada minat kunjungan remaja ke PIKR sebelum dan sesudah dilakukan kegiatan dengan penayangan media audio visual. Analysis bivarian dengan menggunakan Wilcoxon untuk mengetahui pengaruh peningkatan pengetahuan sebelum dan sesudah diberi penyuluhan.

\section{Hasil Penelitian}

Kegiatan PIKR dilaksanakan setiap sebulan sekali minggu ke dua setiap bulannya. Pada kegiatan pertama dilaksanakan pada tanggal 13 Oktober 2017 pukul 16.00. Jumlah peserta yang hadir adalah 14 orang. Adapun karakteristir responden digambarkan sebagai berikut :

Tabel.1 Gambaran karakteristik responden remaja pada kegiatan PIKR di Kelurahan Bandarjo Ungaran Barat

\begin{tabular}{cccc}
\hline No resp & Jenis Kelamin & Umur & Pendidikan \\
\hline 01 & $\mathrm{P}$ & 24 tahun & D3 \\
\hline 02 & $\mathrm{~L}$ & 17 tahun & SMA \\
\hline 03 & $\mathrm{~L}$ & 21 tahun & Mahasiswa \\
\hline 04 & $\mathrm{P}$ & 17 tahun & SMA \\
\hline 05 & $\mathrm{~L}$ & 18 tahun & SMasiswa \\
\hline 06 & $\mathrm{~L}$ & 15 tahun & SMP \\
\hline 07 & $\mathrm{~L}$ & 14 tahun & SMA \\
\hline 08 & $\mathrm{~L}$ & 17 tahun & SMA \\
\hline 09 & $\mathrm{~L}$ & 18 tahun & SMA \\
\hline 10 & $\mathrm{~L}$ & 18 tahun & SMA \\
\hline 11 & $\mathrm{~L}$ & 17 tahun & SMA \\
\hline 12 & $\mathrm{P}$ & 17 tahun & Mahasiswa \\
\hline 13 & $\mathrm{P}$ & 19 tahun & Mahasiswa \\
\hline 14 & $\mathrm{~L}$ & 24 tahun & \\
\hline
\end{tabular}

Dari gambaran di atas dapat dikatakan bahwa jumlah responden adalah 14 dengan jenis kelamin laki-laki sejumlah 10 orang dan perempuan sejumlah 4 orang 
Tabel. 2 Gambaran Tingkatan Remaja pada kegiatan PIKR di Kelurahan Bandarjo Ungaran Barat Kabupaten Semarang

\begin{tabular}{cc}
\hline Tingkatan Remaja & Jumlah \\
\hline Remaja Awal $(13-15$ tahun $)$ & 3 orang $(21,4 \%)$ \\
\hline Remaja menengah $(16-19$ tahun $)$ & 8 orang $(57,2 \%)$ \\
\hline Remaja Akhir $(20-25$ tahun $)$ & 3 orang $(21,4 \%)$ \\
\hline
\end{tabular}

Dari gambaran di atas dapat dikatakan bahwa sebagian besar responden adalah kategori remaja menengah yaitu usia 16 - 19 tahun sejumlah 8 orang $(57,2 \%)$.

Tabel 3 Gambaran Tingkat Pendidikan Remaja pada kegiatan PIKR di Kelurahan Bandarjo Ungaran barat Kabupaten Semarang

\begin{tabular}{cc}
\hline Tingkat Pendidikan & Jumlah \\
\hline Pendidikan Dasar (SD, SMP) & 2 orang $(14,3 \%)$ \\
\hline Pendidikan Menengah (SMA) & 7 orang $(50 \%)$ \\
\hline Pendidikan Tinggi (D3/Mahasiswa) & 5 orang $(35,7 \%)$ \\
\hline
\end{tabular}

Dari gambaran di atas dapat dikatakan bahwa tingkat pendidikan responden sebagian besar adalah menengah yaitu tujuh orang atau $50 \%$

Pada pertemuan ini kegiatan PIKR dilaksanakan dengan pemberian materi tentang bahaya merokok. Setelah dilakukan pemutaran video tentang bahaya merokok, peneliti mengidentifikasi kondisi responden

Pelaksanaan kegiatan PIKR dengan menggunakan media audio visual dengan materi HIV/AIDS dilaksanakan pada hari Sabtu tanggal 11 Nopember 2017 pada pukul 16.00. Jumlah yang hadir adalah 18 remaja. Sebelum melakukan pemutaran film, peneliti melakukan pengukuran pengetahuan remaja tentang HIV/AIDS, selama 15 menit. Selanjutnya peneliti melakukan kegitan pemutaran film HIV/AIDS dengan durasi sekitar 15 menit. Peneliti memberi kesempatan kepada remaja untuk bertanya tentang film yang sudah ditayangkan. Setelah itu, peneliti melakukan evaluasi pengetahuan remaja. Gambaran pengetahuan remaja tentang HIV/AIDS adalah sebagai berikut:

Tabel 3 Gambaran pengetahuan responden tentang HIV/AIDS pada kegiatan PIKR di Kelurahan Bandarjo Ungaran Barat

\begin{tabular}{ccccc}
\hline Pengetahuan & Mean & Median & Nilai minimum & Nilai Maksimum \\
\hline Pre tes & 14,33 & 16 & 4 & 18 \\
\hline Post tes & 17,28 & 18,00 & 10 & 19 \\
\hline
\end{tabular}


Langkah selanjutnya peneliti melakukan uji normalitas data. Uji normalitas data menggunakan Shapiro-Wilk karena jumlah sampel 18 orang. Uji normalitas data menunjukkan angka pengetahuan sebelum penayangan audio visual menunjukkan nilai 0,001 dan pengetahuan sesudah penayangan audio visual menunjukkan nilai 0,000 dapat dikatakan bahwa data tidak normal. Sebagai gambaran ditunjukkan dalam tabel berikut:

Tabel 4 Gaambaran uji normalitas data responden tentang HIV/AIDS pada kegiatan PIKR di Kelurahan Bandarjo Ungaran Barat

\begin{tabular}{ccccccc}
\hline & \multicolumn{3}{c}{ Kolmogorov-Smirnov } & \multicolumn{3}{c}{ Shapiro-Wilk } \\
\cline { 2 - 7 } & Statistic & df & sig & Statistic & df & sig \\
\hline Pengetahuan pre & 0,206 & 18 & 0,041 & 0,769 & 18 & 0,001 \\
\hline Pengetahuan post & 0,281 & 18 & 0,001 & 0,692 & 18 & 0,000 \\
\hline
\end{tabular}

Setelah dilakukan uji normalitas data, dan telah diketahui data tidak normal, maka peneliti melakukan transformasi data. Hasil transformasi data menunjukkan data sebagai berikut :

Tabel 5 Gambaran pengetahuan responden tentang HIV/AIDS pada kegiatan PIKR di Kelurahan Bandarjo Ungaran Barat setelah dilakukan transformasi data

\begin{tabular}{ccccc}
\hline Pengetahuan & Mean & Median & Nilai Minimum & Nilai Maksimum \\
\hline Pre test & 1,1241 & 1,2041 & 0,60 & 1,26 \\
\hline Post test & 1,2336 & 1,2553 & 1,00 & 1,28 \\
\hline
\end{tabular}

Langkah selanjutnya peneliti melakukan uji normalitas data setelah dilakukan transformasi data. Uji normalitas data dengan menggunakan Shapiro-Wilk menunjukkan hasil pengetahuan sebelum penayangan audio visual menunjukkan nilai 0,000 dan setelah dilakukan penayangan audio visual menunjukkan nilai 0,000

Sebagai gambaran uji normalitas data dapat ditunjukkan tabel sebagai berikut :

Tabel 6 Gambaran Uji Normalitas Data tentang HIV/AIDS pada kegiatan PIKR Kelurahan Bandarjo Ungaran Barat.

\begin{tabular}{lcccccc}
\hline & \multicolumn{2}{c}{ Kolmogorov-Smirnov } & \multicolumn{3}{c}{ Shapiro-Wilk } \\
\cline { 2 - 7 } & Statistic & df & sig & Statistic & df & sig \\
\hline Pengetahuan pre & 0,266 & 18 & 0,002 & 0,633 & 18 & 0,000 \\
\hline Pengetahuan post & 0,314 & 18 & 0,00 & 0,613 & 18 & 0,000 \\
\hline
\end{tabular}

Uji Wilcoxon menunjukkan nilai signifikansi 0,001 dengan kesimpulan ada perbedaan pengetahuan sebelum dan sesudah diberi media audio visual pada remaja PIKR kelurahan Bandarjo Ungaran Barat. 


\section{Pembahasan}

Berdasarkan penelitian di atas, penulis mencoba melakukan pembahasan terkait hasil penelitian yang telah dilakukan. Penelitian secara deskriptif analitik ini untuk melihat gambaran kunjungan remaja pada kegiatan PIKR di Kelurahan Bandarjo Ungaran Barat, dilakukan saat jadwal kegiatan PIKR yaitu pada minggu pertama setiap bulan. Peneliti melakukan dua kali kunjungan, selama dua bulan. Pertemuan pertama melakukan pengkajian dan melihat jumlah pengunjung remaja dan pemberian penayangan video dengan topik Bahaya Merokok. Jumlah kunjungan remaja adalah 14 orang. Pada pertemua kedua peneliti melakukan penayangan video dengan topik HIV/AIDS. Jumlah kunjungan remaja adalah 18 orang. Kemudian pada kunjungan kedua ini peneliti melanjutkan analisis melihat perbedaan pengetahuan sebelum dan sesudah diberi media audio visual. Dengan uji Wilcoxon didapatkan nilai signifikansi 0,001 berarti ada perbedaan pengetahuan sebelum dan sesudah penayangan media audio visual HIV/AIDS.

PIKR adalah suatu kegiatan remaja yang berada dibawah naungan BKKBN, sehingga topik yang disampaikan juga mengacu pada program yang telah ditetapkan oleh instansi tersebut. Dalam hal ini peneliti memberikan topik tentang bahaya merokok dan HIV/AIDS. Beberapa penelitian terkait diantaranya penelitian yang dilakukan oleh Firmansyah Dimas Bayu, Asmuji, dan permatasari Elok tentang Hubungan Peran PIKR dengan Perilaku Menyimpang Seksual pada Remaja di SMA Negeri 4 Jember menunjukkan hasil tidak ada hubungan antara peran PIKR dengan perilaku menyimpang seksual, dengan nilai 0,598 lebih besar dari 0,05. Penelitian lain dilakukan oleh Nunung Desyolmita dan Firman dengan materi Hubungan Persepsi Dengan Peranan Siswa Dalam Pelaksanaan PIKR reproduksi Remaja di SMP N 2 Pariaman menunjukkan hasil ada hubungan yang signifikan antara persepsi dengan peranan siswa dalam pelaksanaan program kegiatan PIKR dengan Pearson correlation sebesar 0, 946 dan signifikasi 0,000 dengan tingkat hubungan kuat sekali.

Penelitian lain yang dilakukan oleh Aisyah Larasati, Lismi An'imatul Chisbiyah dan Laili Hidayati tentang Penerapan Fokus Grup DiskussionUntuk Mengevaluasi Kualitas Layanan Jurusan Teknologi Industri menunjukkan hasil factor yang mempengaruhi persepsi mahasiswa terhadap penilaian kualitas layanan yang diberikan jurusan antara lain : kualitas 
dosen, sarana dan prasarana, kurikulum, kegiatan mahasiswa, tenaga laboran, pelayanan administrasi akademik dan informasi peluang karier. Penelitian lain yang dilakukan oleh Yati Afiyanti dengan judul Focus Grup Discussionsebagai Metode pengumpulan Data penelitian kualitatif dengan hasil bahwa terbukti banyak digunakan untuk pengumpulan data di berbagai proyek penelitian kualitatif, tetapi tidak selalu menjadi teknik / cara yang paling tepat untuk mengumpulkan data.

\section{Kesimpulan}

Gambaran pelaksanaan kegiatan PIKR dengan menggunakan media audio visual dengan materi Bahaya Merokok di Kelurahan Bandarjo Ungaran Barat dengan indikator jumlah remaja yang hadir 14 remaja dengan 10 remaja laki-laki dan 4 remaja perempuan. Tingkatan remaja (remajaa awal 13-15 tahun sejumlah 3 orang atau 21,4\%, remaja menengak 16-19 tahun sejumlah 8 orang atau 57,2\% dan remaja akhir 20-25 tahun sejumlah 3 orang atau 21,4\%). dan tingkat pendidikan remaja adalah pendidikan dasar (SD,SMP) sejumlah 2 orang atau 14,3\%, pendidikan menengah (SMA/SMK) sejumlah 7 orang atau 50\%, dan pendidikan tinggi (D3/mahasiswa) sejumlah 5 orang atau $35,7 \%$. Gambaran pelaksanaan kegiatan PIKR dengan menggunakan media audio visual dengan materi HIV/AIDS di Kelurahan bandarjo Ungaran barat dengan indikator jumlah remaja yang hadir adalah 18 remaja, ada perbedaan pengetahuan sebelum dan sesudah diberi materi tentang HIV/AIDS dengan signifikansi 0,001

\section{Saran}

\section{Bagi Remaja}

Perlu peningkatan motivasi dalam lemakukan kegiatan yang bermanfaat bagi remaja agar tidak terjerumus dalam pergaulan yang negative. Mengingat masa remaja adalah masa yang sangat rawan.

\section{Bagi Kelurahan Bandarjo}

Hendaknya dapat meningkatkan kerjasama yang sudah baik ini agar remaja lebih termotivasi untuk melakukan kegiatan, dan merasa bagian yang penting sebagai anggota masyarakat. 


\section{Bagi Pemegang Program PIKR}

Terutama bagi pemerintah khususnya pemegang program baik yang ada di kelurahan maupun kecamatan, kerjasama yang sudah terjalin perlu ditingkatkan koordinasinya, untuk kerjasama dengan instansi terkait misalnya dinas social, dinas tenaga kerja, dinas pendidikan dan sebagainya.

\section{Bagi peneliti Selanjutnya}

Agar meneliti dengan variable atau metode yang lain dalam upaya meningkatkan minat remaja pada kegiatan PIKR ini, misalnya dengan metode forum grup diskusi. 


\section{Daftar Pustaka}

Arikunto, 2006, Prosedur Penelitian Suatu Pendekatan Praktek, Edisi IV, Rineka Cipta, Jakarta

Aisyah L, dkk, Penerapan Fokus Grup Discussion Untuk Mengevaluasi Kualitas layanan Jurusan Teknologi Industri, Skripsi, 2013

Firmansyah DB, dkk, Hubungan Peran PIK-R (Pusat Informasi Dan Konseling Remaja) Dengan perilaku Menyimpang Seksual Pada Remaja di SMAN 4 Jember, Skripsi, 2014

Kusyogo C, dkk, Perencanaan Dan Evaluasi Promosi Kesehatan Masyarakat Dan petunjuk Pembuatan Tugas, Bagian Promosi Kesehatan Dan Ilmu perilaku Fakultas Kesehatan Masyarakat Universitas Diponegoro, ad-mediakreatif, 2016

Nunung D, dkk, Hubungan Persepsi Dengan Peranan Sisiwa Dalam Pelaksanaan program Kegiatan Pusat Informasi Konseling Kesehatan Reproduksi Remaja di SMP N 2 Pariaman, Skripsi, 2013

Soekidjo Notoadmodjo, 2010, Promosi Kesehatan Teori dan Aplikasi, Rineka Cipta, Jakarta

Yati A, Focus Grup Discussion (Diskusi Kelompok Terfokus) Sebagai metode pengumpulan Data Penelitian Kualitatif, Skripsi, 2008 